\title{
Exploring the Molecular Landscape of Host-Parasite Coevolution
}

\author{
D.E. ALLEN AND T.J. LitTLE \\ Institute of Evolutionary Biology, University of Edinburgh, Edinburgh EH9 3JT, Scotland, United Kingdom \\ Correspondence: desiree.allen@ed.ac.uk
}

\begin{abstract}
Host-parasite coevolution is a dynamic process that can be studied at the phenotypic, genetic, and molecular levels. Although much of what we currently know about coevolution has been learned through phenotypic measures, recent advances in molecular techniques have provided tools to greatly deepen this research. Both the availability of full-genome sequences and the increasing feasibility of high-throughput gene expression profiling are leading to the discovery of genes that have a key role in antagonistic interactions between naturally coevolving species. Identification of such genes can enable direct observation, rather than inference, of the host-parasite coevolutionary dynamic. The Daphnia magna-Pasteuria ramosa host-parasite model is a prime example of an interaction that has been well studied at the population and whole-organism levels, and much is known about genotype- and environment-specific interactions from a phenotypic perspective. Now, with the recent completion of genome sequences for two Daphnia species, and a transcriptomics project under way, coevolution between these two enemies is being investigated directly at the level of interacting genes.
\end{abstract}

Charles Darwin appears to have had little appreciation for parasites. His neglect was probably symptomatic of the mood of naturalists of his time: Parasites were viewed as degenerate and generally unworthy of the attention of sensible Victorian naturalists. This is unfortunate, because the field of parasitology offers some of the most striking and elegant examples of adaptation that could no doubt have aided Darwin's efforts to have his theory of natural selection gain acceptance. Indeed, it is now clear that parasites and pathogens offer paradigmatic examples of evolution in action: Due to their often short generation time, they can be observed evolving in the laboratory (Rainey 2004; Morgan et al. 2005) and even in the real world, as evidenced by the evolution of drug resistance (Marchese et al. 2000), emerging diseases (Morse 1994), and vaccine escape mutants (Bangham et al. 1999). Of course, parasite adaptation is only half the story, and host defense systems offer equally striking, indeed strikingly complex, examples of adaptation. Thus, the host-parasite interaction is a dynamic coevolutionary relationship. Darwin was clearly aware of the importance of some coevolutionary scenarios (in particular, pollination), but the ramifications of hostparasite coevolution were not among them. Today, there remains considerable need to understand the nature and full significance of antagonistic parasitic interactions.

For example, dynamic ongoing adaptation and counteradaptation between hosts and parasites may foster diversity within species and influence their mode of reproduction. Computer simulations have confirmed that parasitic interactions should promote diversity (Clarke 1979; Seger 1988; Hamilton et al. 1990; Frank 1993), and indeed, immune system genes may show striking levels of polymorphism (Hill et al. 1992; Hedrick 1994, 1998; Bishop et al. 2000; Obbard et al. 2008). Therefore, an explanation for genetic differences in susceptibility, which are pervasive in parasitic interactions (Little 2002; Woolhouse et al. 2002), is that a dynamic coevolutionary process has promoted these differences and will determine the fate of genetic variants. These dynamics can be important on medically relevant timescales (e.g., in vector control programs), but, even in longer-lived hosts, genetic data need to be interpreted in terms of host-parasite coevolution (e.g., the genetic polymorphism that underlies sickle cell anemia) (Hill et al. 1991; Gilbert et al. 1998). They are also of broad evolutionary importance: Frequency-dependent dynamics of host and parasite genes may select for recombination, and thus parasitism offers an explanation for why sexual reproduction predominates in metazoan organisms (The Red Queen Hypothesis) (Hamilton 1980; Lively 1993; Salathé et al. 2008).

Despite our knowledge of the occurrence of genetic variation for disease-related traits, we lack a thorough understanding of the coevolutionary dynamic. For instance, the predominant selective force during coevolutionary interactions could be selective sweeps, where genetic polymorphism is transient, observable only as one genotype rises to fixation, leaving populations in a single state that remains until the next mutation arises. Alternatively. there could be frequency-dependent selection where common genotypes are disfavored, such that no single genotype can go to fixation and rare genotypes never become extinct. An additional nuance is that the fixation of successful genotypes may be prevented by trade-offs, for example, if a resistance allele confers poor fitness in parasite-free environments. A more general form of the trade-off hypothesis is that polymorphism might further be maintained by pervasive genotype-by-environment interactions, where alternative host genotypes are favored under different environmental conditions. Without an understanding of these mechanisms, we lack the capacity to determine the rate at which evolu- 
tion occurs in host-parasite interactions and the likely outcomes for the health of host populations.

Modern molecular approaches hold the key to unraveling the intricacies of the coevolutionary process. Molecular techniques have successfully identified immune system genes that control infection, and this explosion of genetic information is fertile ground for advancing our understanding of coevolution. Much work in the molecular study of immune systems has been confined to organisms of obvious medical relevance (e.g., humans) or those that are standard models for genetic study (e.g., mice and Drosophila). However, these organisms are either too long-lived to permit observations of genetic change within reasonable time frames, there is a lack of suitable knowledge regarding their natural parasites, or they are not amenable to experimentation. Thus, the study of evolution at immune genes remains incomplete, and the contribution of genomics to the understanding of coevolution is less than it could be.

Study systems are required that can provide a comprehensive view on host-parasite interactions, i.e., systems that are amenable to (1) gene discovery in both host and parasite, (2) experimental manipulation including wholeorganism experimentation with parasites/pathogens, and hence, measurement of fitness and phenotypes, and (3) epidemiological or evolutionary studies in the field. Ideally, all such studies will concern naturally coevolving interactors as opposed to artificial interactions or the use of pathogen mimics (although these methods certainly have merits for some questions). Biology's major metazoan models (e.g., Caenorhabditis and Drosophila) tend to fulfill criterion 1 but fall short on 2 and 3, especially with respect to the use of naturally coevolving interactors (but see Bangham et al. 2008). In contrast, the crustacean Daphnia has historically strong credentials in the second two categories, and it is developing rapidly in terms of gene discovery projects. This chapter briefly discusses the development of molecular techniques that can be used to elucidate the genetic underpinnings of host-parasite interactions and then describes how these tools can and have been used in the context of Daphnia and its parasites, in conjunction with more traditional phenomenologicalbased approaches, to provide a unique opportunity to study host-parasite coevolution in a multifaceted way.

\section{METHODS OF GENE DISCOVERY: PHYLOGENETIC CANDIDATE GENE APPROACHES}

In the absence of any a priori information on immune system genes in a particular species, the best available option for locating genes of interest is de novo sequencing using degenerative primers designed from genes in a closely related species. Once the gene of interest is sequenced, inference as to its associated function can be made and phylogenetic comparisons with other closely related species can elucidate the evolutionary context. Depending on the genetic distance between the focal species and the species used to design primers, this method will have variable success. Moreover, it is constrained as to the information that it can reveal about the immune system of the focal species by the immune system of the related species from which the original sequence information was obtained; novel immune mechanisms will be overlooked. Finally, this method is limited in its utility except for highly conserved immune/infection-related pathways and may be of little use for rapidly evolving genes, although even highly conserved genes may have regions within them that evolve rapidly (Little et al. 2004; Little and Cobbe 2005). However, as the only option for gene discovery in some species, this is often a useful first pass.

\section{METHODS OF GENE DISCOVERY: QUANTITATIVE TRAIT LOCI}

Quantitative trait locus (QTL) or association mapping is a means of identifying chromosomal regions containing genes underlying a phenotype of interest, such as those produced during host-parasite interactions. This is achieved via crossing, phenotyping, and genotyping progeny in the laboratory. Specifically, this is a laborintensive method requiring a linkage map, mapping populations consisting of genetic crosses between highly homozygous lines (often requiring generations of inbreeding or backcrosses) or a well-established pedigree. Additionally, a large number of microsatellite or singlenucleotide polymorphism (SNP) markers are required in order to have the statistical power to locate the genomic regions conferring the phenotype. Although quite involved, and not suitable for all species (especially those that reproduce poorly in the laboratory), QTL and association mapping have been a highly effective means of identifying genes involved in host-parasite interactions (see, e.g., Niaré et al. 2002; Lazzaro et al. 2004). QTL analyses have been put to particularly good use in plants: Due to their tractability to genetic crossing and the production of large sample sizes, the genetic bases of plantpathogen interactions have been widely elucidated through this technique (for references, see Kover and Caicedo 2001; Wilfert and Schmid-Hempel 2008).

Fine-scale genetic mapping via the QTL approach is useful for gene discovery even without the advantage of a whole-genome sequence. If a chromosomal region can be narrowed sufficiently, through sequential crosses or backcrosses, de novo sequencing can identify genes within the region. This provides the material for comparison against known sequences from other taxa and may lead to the actual gene or genes responsible for the phenotype of interest. Obviously, with the availability of a genome sequence, identifying the genes within the QTL region becomes simpler. Even in this case, however, the genes within a located QTL region will not necessarily be identifiable as underlying the phenotype of interest, and it is important to bear in mind that wholly novel (i.e., genes that have not been characterized as immunity genes in any organism) genes could be the key genes. To overcome such limitations, it can be valuable to look at the expression pattern of all genes, and putative genes, located within the identified region. Using microarray, quantitative polymerase chain reaction (Q-PCR), or next-genera- 
tion sequencing approaches (detailed below), any changes in expression patterns during exposure to experimental conditions can be monitored and the gene or genes responding to the challenge can be identified (Brown et al. 2005).

In addition to providing information on the location of chromosomal regions, and potentially the actual genes underlying a particular phenotype, QTL mapping can provide information on the way genes interact to produce a phenotype. The field of quantitative genetics has wellestablished methods for determining the additive, dominance, and epistatic interactions of alleles and loci (Lynch and Walsh 1998). Indeed, in a recent review of QTL studies of parasite/pathogen susceptibility, Wilfert and SchmidHempel (2008) were able to extract details about the number and effect of genes involved, concluding that resistance is based on few loci, and both additive and epistatic effects are important. These researchers also assessed the implications for evolutionary puzzles such as the evolution of sex and suggest that epistasis in resistance may have a major impact on the evolution and maintenance of meiotic segregation and recombination.

\section{METHODS OF GENE DISCOVERY: GENE EXPRESSION}

The development of microarrays, pyrosequencing technology, and next-generation massively parallel sequencing methods has introduced high-throughput means of discovering genes and gene networks underlying host and parasite traits and interactions (Hill et al. 2005; Keeler et al. 2007; Baton et al. 2008). These technologies have enabled the field to move from the previously described steps of inferring gene involvement through phylogenetic relationships or associating quantitative traits with genetic regions to directly measuring transcriptional changes in potentially hundreds of different genes during the production of a particular phenotype. As with most new molecular technology, these techniques were originally only cost-effective for well-established genetic systems. However, technology has now advanced to the point where these techniques are readily available for essentially any organism of interest. The main difference in the utility of transcriptional profiling compared to QTL analyses is that the latter can locate genes that do not show differential regulation during infection (e.g., vertebrate major histocompatibility genes are important, but only constitutively expressed), whereas the former can uncover up-regulation or down-regulation of a gene and as such might overlook parts of the immune system.

Transcriptional profiling, either via microarray or sequencing of cDNAs, can be used both to identify genes or pathways underlying the trait of interest or to specifically look at transcriptional profiles of target genes. Tissue-specific gene expression arrays are often preferred in medical and veterinary research, but where little is known about the genetic basis of the trait of interest, whole-genome microarrays or cDNA sequencing can be used. This process is effective for detecting the genetic basis of both host immune responses and parasite infec- tion strategies. Differential gene expression between exposed and unexposed individuals has been used to simultaneously identify hundreds of genes underlying resistance phenotypes in a diverse range of organisms, such as cattle responding to intestinal nematodes (Araujo et al. 2009), Anopheles as a vector responding to Plasmodium (Vlachou et al. 2005), and shrimp exposed to white spot syndrome virus (Lan et al. 2006). In a similar manner, differential expression of genes underlying infection traits, such as the fungal pathogen Metarhizium's response to different insect hosts' cuticles (Freimoser et al. 2005), is key to identifying genes determining a parasite's coevolutionary trajectory.

In addition to its use in de novo gene identification, transcriptional profiling can be used on a narrower range of genes, such as those located within a QTL region or previously identified as underlying a phenotype of interest. When used in combination with QTL mapping, not only can gene expression changes be used to locate the specific genes within these regions that are underlying the trait, but the expression profile itself can subsequently be treated as a quantitative trait and the heritability and genetic architecture of gene expression identified (Brem et al. 2002).

Once genes are identified via any of the described methods, further gene expression measurement can be used to verify their involvement in the phenotype of interest, and this is probably best done on individual genes using quantitative reverse transcription PCR (qrtPCR) as opposed to further use of large-scale methods. However, the true power of transcriptional profiling for illuminating host-parasite coevolution is that it can be used in an experimental context, particularly once target genes are identified. Understanding how specific genes respond to genetic and environmental variation is fundamental to our understanding of coevolution. Thus, using appropriately designed experiments, questions can be asked of any system and the differential expression of genes can be measured, rather than the associated phenotype.

\section{DAPHNIA}

Large swathes of data are rarely of use unless they can be contextualized. With the advent of technology enabling the production of information such as wholegenome transcriptional profiling, the onus is on us to develop ways to apply these data to questions of broader relevance. Medical, veterinary, and agricultural areas of research use these technologies for purposes such as the development of vaccines and the breeding of animals or plants more resistant to specific parasites or pathogens. However, evolutionary biologists have a different agenda, i.e., to elucidate the mechanisms underlying evolutionary change. With our work on the crustacean Daphnia, we are specifically interested in host-parasite coevolutionary change, and thus our goal is to apply these molecular techniques to questions more traditionally addressed using phenomenological, whole-organism studies. By integrating these two approaches in the Daphnia hostparasite system, we can hope to address not only the genetic basis of host-parasite interactions, but also the 
role of genetic and environmental variations underlying coevolution in general.

\section{Daphnia and the Potential for Coevolution}

Daphnia are small ( $\sim \mathrm{mm})$ ubiquitous crustaceans that have been the focus of more than a century of intense and diverse study, including toxicology, life history, physiology, nutrition, and parasitology. Critically, the distribution and virulence of the prevalent bacterial, microsporidian, and fungal parasites of Daphnia have been characterized, and easy to perform experimental manipulations on these naturally coevolving parasites have revealed extensive genetic variation for susceptibility (Ebert et al. 1998; Little and Ebert 1999, 2000b, 2001; Carius et al. 2001). Especially useful is the fact that Daphnia are facultative parthenogens; thus, they can be maintained clonally in the laboratory, enabling precise comparison of genetic backgrounds or the study of different environments on replicates of the same genetic background. They can also reproduce sexually, which permits traditional crossing experiments, with the caveat that sexual reproduction is mediated by environmental conditions to which genotypes vary in their sensitivities.

The short generation time of Daphnia ( 10 d) enables the study of real-time evolutionary responses to parasites (Little and Ebert 1999). Gathering epidemiological data is also straightforward: The clear carapace of Daphnia makes infections easy to identify in the field, and infection dynamics can be tracked. Epidemics are common and severe but highly variable in space and time (see, e.g., Duncan et al. 2006; Lass and Ebert 2006; Duffy and SivarsBecker 2007; Duncan and Little 2007; Wolinska et al. 2007). Past work has shown that Daphnia genotype frequencies (identified by neutral molecular markers) fluctuate wildly (Hebert 1974) and that these dynamics are linked to infection (Little and Ebert 1999; Mitchell et al. 2004; Duncan and Little 2007). Such studies were a reasonable, if rough, approximation of parasite-driven dynamics. In the postgenomic era, however, we can do much better through the identification and tracking of genes that specifically influence infection outcomes.

Simultaneous comparison of both host and parasite genetic backgrounds has lead to the discovery of genetic specificity in the interaction between Daphnia magna and its bacterial pathogen Pasteuria ramosa (Carius et al. 2001). Genetic specificity should not be confused with immunological specificity of the sort that is commonly generated by vertebrate immune systems and possibly by some invertebrates as well (Little et al. 2003; Sadd and Schmid-Hempel 2006). Immunological specificity is the case where the immune system learns to recognize and rapidly respond to a particular pathogen genotype (more specifically, a particular antigen) and does not explicitly take account of host genetic variation. Genetic specificity is about simultaneous genetic variation in hosts and parasites and, in particular, when the ability to resist parasites is tightly dependent on which parasite genotype is encountered (irrespective of previous encounters), whereas the ability of a particular parasite genotype to establish infec- tion is tightly dependent on which host genotype it encounters (again, irrespective of infection history). Thus, genetic specificity is defined as host genotype by parasite genotype interactions (hereafter, referred to as $G_{H} \times G_{P}$ )

Genetic specificity indicates the potential for frequency-dependent coevolution. Many studies have determined genes that have a key role in resisting parasites or pathogens (e.g., in Anopheles Gambiae; see, e.g., Osta et al. 2004), whereas fewer studies have used variable hosts as a starting point to detail genes that have a role in genetic variability for infection. No studies that we are aware of on animals (the plant literature is, however, comparatively rich; see, e.g., Thompson and Burdon 1992; Stahl and Bishop 2000) have used host and parasite combinations that show tight patterns of genetic specificity as a starting point for gene discovery. This, however, would be the ideal scenario given the relationship between genetic specificities and the coevolutionary process.

\section{Daphnia Genomics: Characterizing the Immunome}

Any gene discovery research program finds a strong foundation on a full-genome sequencing project, with Daphnia being no exception. The first crustacean genome to be fully sequenced was that of Daphnia pulex. Using sequence homology with the immune systems of other arthropods, 82 genes and 21 gene families with putative immune function were identified in D. pulex (McTaggart et al. 2009). This study identified pathways such as the TOLL pathway that are well conserved across invertebrate taxa and characterized areas of the Daphnia immune system that may be missing or evolving rapidly relative to other arthropods, such as antimicrobial peptides and antiviral RNA interference (RNAi) genes, respectively.

Although D. pulex is not suited for experimental hostparasite studies, its full-genome sequence has enabled the characterization of its innate immune system and provided a first set of candidate genes for study in a species well established for the study of host-parasite interactions, D. magna. Several genes identified from this genome sequence have been used for subsequent analysis in D. magna. Full cDNAs for one prophenyloxidase and two nitric oxide synthetase genes were acquired for $D$. magna (Labbé and Little 2009; Labbé et al. 2009). Using qrtPCR, changes in host-gene expression levels were measured in response to exposure to the bacterial parasite P. ramosa. The host and parasite genotypes used in these expression experiments have been studied previously (Carius et al. 2001), with this particular parasite genotype eliciting a high rate of infection in some genotypes but not in others. Despite this, there was no significant upregulation of any of the three genes tested, suggesting that they may not be directly involved in response to infection. This result was somewhat surprising, given that the genes studied almost invariably have a role in immunity in other taxa (Soderhall and Cerenius 1998; Rivero 2006). However, further testing is needed to draw conclusions about their potential role in generating resistant phenotypes in Daphnia. In particular, given the large variation typically observed among Daphnia genotypes (Little and 
Ebert 2000b; Carius et al. 2001), it will be crucial to compare expression levels of a larger number of genotypes that vary in their resistance capabilities.

A major limitation of this type of gene discovery approach is that any immune system genes novel to the focal species will not be identified. Although the full-genome sequence of $D$. magna has now also been completed (see http://wfleabase.org/), any genes identified via phylogenetic comparison will still be restricted to those already known in other taxa. Furthermore, this approach assumes that if a gene has an immune function in one species (typically a well-characterized species such as Drosophila melanogaster), it will also be immunity related in the focal species. Although this assumption may be reasonable for genes that appear to have a universal role in immunity (e.g., prophenoloxidase, nitric oxide synthethase, $\alpha-2$-macroglobulins), it is unlikely to always hold true. Thus, our current research is directed toward finding genes underlying coevolutionary traits specifically in D. magna. Toward this end, a transcriptomics project designed to identify genes specifically involved in the D. magna-P. ramosa interaction has been initiated.

Rather than sequencing a single genotype, an experimental design was used that enables both gene identification and experimental comparison. Two host genotypes, one resistant and one susceptible, and a single parasite strain were used in a $2 \times 2$ design whereby each of the two host genotypes were used to produce an unexposed control sample and an exposed treatment sample. The gene expression profiles of these four samples will produce (1) a comparison between the standing level of gene expression in susceptible and resistant individuals, (2) a comparison between the susceptible and resistant individuals' gene expression levels during exposure to a parasite, and (3) changes in gene expression between exposed and unexposed individuals of the same genotype. The differential regulation of genes in the two samples exposed to $P$. ramosa relative to their controls should provide a fairly comprehensive list of genes potentially underlying the innate immune response of $D$. magna. However, it will be desirable to expand this work to include additional genotypes.

\section{FROM GENE DISCOVERY TO COEVOLUTION}

Although identifying host genes that respond to parasite exposure is a major advance in understanding the Daphnia immune system, it is simply a first step toward our understanding of coevolutionary processes. Coevolution is clearly a dynamic, ongoing process, and thus, the genes involved must be characterized in terms of past selection pressure, current standing variation, and interaction with factors affecting their potential for evolutionary change. To this end, we are interested in applying standard molecular evolution analyses (e.g., McDonald Kreitman tests; McDonald and Kreitman 1991), laboratory experimental manipulations, and field-based samples and experiments to the set of genes identified from the transcriptome and to the set identified via bioinformatics comparison (McTaggart et al. 2009).

\section{MOLECULAR EVOLUTION}

Once candidate genes have been identified through differential gene expression, they can be subject to standard analyses of molecular evolution in order to examine the evolutionary history and signatures of selection on these genes. This information can be gained through the study of DNA polymorphism and divergence. It is, for example, possible to identify genes that are evolving rapidly, and thus possibly engaged in a host-parasite arms race (Yang and Bielawski 2000; Ford 2002). Strong directional selection, such as that which occurs during a host-parasite arms race, is expected to increase the rate of amino acid substitution among species, and the concomitant spread of new advantageous alleles will reduce the level of within-species genetic diversity around the selected locus. If, on the other hand, there is negative frequency-dependent selection, where rare alleles are at a selective advantage, genetic diversity will be maintained for extended periods of time and divergence between haplotypes can become the extreme, as is seen, for example, at vertebrate major histocompatibility complex (MHC) loci (see, e.g., Hedrick 1998) and in plant resistance genes (Stahl et al. 1999).

The detection of arms races requires an outgroup species that is neither too distantly related to the focal species (such that there is saturation of nucleotide divergence) nor so closely related that nucleotide differences are too scarce for analyses. This problem, for example, is particularly acute in the study of mosquitoes, which tend to form species flocks with little diversity within flocks but substantial (too substantial for outgroup comparisons) divergence between flocks (Obbard et al. 2007, 2009). The number and average genetic distance separating Daphnia species suggest that this is unlikely to be a problem in this genus (Colbourne et al. 1998). Indeed, we have found $D$. pulex $-D$. parvula comparisons to be effective for the detection of arms races (S McTaggart and T Little, in prep.), although similar efforts on $D$. magna have yet to be undertaken. The detection of negative frequency-dependent selection or other forms of balancing selection faces different but equally challenging issues. In particular, it can be difficult to distinguish balancing selection from relaxed constraint, because both forces can lead to very high polymorphism. Data on linkage disequilibrium can to a considerable degree resolve the issue, but even with this in hand, other factors, such as gene conversion, can potentially derail interpretation (Obbard et al. 2008). Despite these obstacles, there are many instances where analyses of molecular evolution have yielded insight into the evolutionary and coevolutionary process (see, e.g., Hedrick 1998; Hurst and Smith 1999; Stahl et al. 1999; Lazzaro and Clark 2001, 2003; Schlenke and Begun 2003; Lazzaro et al. 2004; Jiggins and Kim 2006; Obbard et al. 2006)

\section{EXPERIMENTAL GENOMICS}

The utility of identifying genes underlying traits involved in coevolution is not limited to elucidating historical patterns of natural selection via molecular evolution approaches but rather can be extended to actual 
laboratory and field experimental applications. Much of our understanding of Daphnia coevolution has come from whole-organism empirical work revealing the impact of both host and parasite genotypes and various aspects of the environment on this interaction. Now, with candidate genes in hand, we can rework these experiments and identify the genetic changes or dynamics that result in phenotypic variation due to $\mathrm{G}_{\mathrm{H}} \times \mathrm{G}_{\mathrm{P}}$ or $\mathrm{G} \times \mathrm{E}$ interactions. For example, host by parasite genetic interactions have been experimentally identified as being a key determinant of infection in the D. magna-P. ramosa system (Carius et al. 2001). It is now possible to repeat this type of laboratory interaction experiment and directly associate the phenotypic response with allelic or nucleotide variation in genes previously identified as underlying resistance or susceptibility. This information is key to determining which genes may be ongoing targets of selection during coevolution.

Extending this, a unique power of the Daphnia system is the capacity to verify the "real world" relevance and evolution of any genes highlighted by QTL or expression studies. Comparing the genotype(s) of naturally infected individuals to that of naturally uninfected individuals can reveal whether these genetic variants determine which individuals become infected and which do not in nature. Normally, verification might be accomplished with experimental knockout lines in the laboratory, but a disease association in natural populations, where the focal gene is found within a huge range of genetic backgrounds, is a different but perhaps more relevant form of verification. Moreover, these data are crucial because they also check for the phenotypic consequence of a gene when placed in a range of environments. Previous work on Daphnia has shown the influence of environmental variables that effect certain genotypes more than others, i.e., there are strong genotype by environment $(\mathrm{G} \times \mathrm{E})$ interactions in the lab (Mitchell et al. 2005; Vale et al. 2008), as have studies on other parasitic interactions (see, e.g., Blanford et al. 2003). Genotype by environment effects are not limited to invertebrates. For example, the widely used mouse strains BALB/c and C57BL/6 clearly differ in susceptibility to parasites under tightly controlled conditions, but they may show no such differences in a natural arena (Scott 1991). Thus, in any taxon, strong $\mathrm{G} \times \mathrm{E}$ interactions could generate a gene infection association in one environment, such as the lab where the QTL or expression work occurred, but no association in other environments such as the field. We stress that the clearest measure of a gene's significance in the host-parasite interaction is that its effects penetrate noisy natural environments in a range of genetic backgrounds.

In this sense, this information is interesting simply from the point of view of understanding how immune effector systems variably respond under genetic and environmental variation. We see a need for the field of immunology to expand to systems tractable for the study of variation or to incorporate variation into existing systems. The experimental designs traditionally used in the field of immunology are simplified: Most experiments are performed in the absence of pathogens, under ideal laboratory conditions, and in homogeneous inbred genetic backgrounds. Thus, although it provides the necessary mechanistic backbone for studying infection, immunology has not typically addressed variation in natural populations, despite the observation that the impact of genetic and environmental variation on infection is likely large (Boulinier et al. 1997; Sorci et al. 1997; Coltman et al. 1999; Little 2002; Thomas and Blanford 2003; Bedhomme et al. 2004; Mitchell et al. 2005; Vale et al. 2008), as are $\mathrm{G} \times \mathrm{E}$ effects (references above). It remains a salient challenge for both immunologists and ecologists to link variation in host-parasite outcomes (as determined by genetic and environmental factors) to immunological mechanisms.

Associations between an immune-related gene and infection in field populations is valuable information, but if possible should be confirmed with phenotypic assays in the laboratory. Here, organisms, such as Daphnia, that reproduce clonally hold great promise because individuals can be brought to the laboratory and maintained as clonal lineages for genotyping and experimentation. Even field-collected infected (and sterilized) individuals can be cured (Little and Ebert 2000a) and kept clonally in the laboratory. By taking a sample of clones (potentially different genotypes) from natural populations, it is possible to effectively establish a snapshot of the population at the time of collection that can then be studied at leisure in the lab. Because many Daphnia parasites can be frozen, snapshots of them can also be taken. These sampling possibilities are relevant because it is important not only to observe allele frequency differences, but ultimately to know how and why they vary, and thus determine the evolutionary consequences for the population. For example, a change in allele frequencies might be accompanied by a decline in parasite prevalence, but that decline might also be the consequence of a change in temperature. By bringing samples of hosts from appropriate time points into the laboratory and testing their phenotypic resistance under controlled conditions, it is possible to verify the cause of gene frequency changes observed in nature.

Such a complete level of information will be difficult to obtain with other prominent host-parasite systems (e.g., Anopheles-Plasmodium), but this level is required when the goal is to elucidate general evolutionary principles. When complete, something specific about the immune pathways of Daphnia will have been uncovered, but more importantly, this research program should also enhance general understanding about the impact of parasitism: How quickly do host genotype frequencies change, how quickly can parasite populations respond, and how will this affect parasite prevalence? The mechanisms by which this occurs are key: Are selective sweeps and transient polymorphisms the norm or does frequency-dependent selection maintain polymorphism? Or maybe it is neither of these. Perhaps polymorphism is maintained by pervasive genotype by environment interactions or epistasis. These are salient questions if we are to understand how coevolution influences the health of populations. 


\section{ACKNOWLEDGMENTS}

T.J.L. and D.E.A. are supported by The Wellcome Trust, United Kingdom.

\section{REFERENCES}

Araujo RN, Padilha T, Zarlenga D, Sonstegard T, Connor EE, Van Tassel C, Lima WS, Nascimento E, Gasbarre LC. 2009. Use of a candidate gene array to delineate gene expression patterns in cattle selected for resistance or susceptibility to intestinal nematodes. Vet Parasitol 162: 106-115.

Bangham C, Anderson RM, Baquero F, Bax R, Hastings I, Koella JC, Lipsitch M, Mclean A, Smith T, Taddei F, et al. 1999. Evolution of infectious diseases: The impact of vaccines, drugs and social factors. In Evolution in health and disease (ed. SC Stearns), pp. 152-160. Oxford University Press, New York.

Bangham J, Kim KW, Webster C, Jiggins FM. 2008. Genetic variation affecting host-parasite interactions: Different genes affect different aspects of sigma virus replication and transmission in Drosophila melanogaster. Genetics 178: 2191-2199.

Baton LA, Garver L, Xi Z, Dimopoulos G. 2008. Functional genomics studies on the innate immunity of disease vectors. Insect Sci 15: 15-27.

Bedhomme S, Agnew P, Sidobre C, Michalakis Y. 2004. Virulence reaction norms across a food gradient. Proc R Soc Lond B Biol Sci 271: 739-744.

Bishop JG, Dean AM, Mitchell-Olds T. 2000. Rapid evolution in plant chitinases: Molecular targets of selection in plantpathogen coevolution. Proc Natl Acad Sci 97: 5322-5327.

Blanford S, Thomas MB, Pugh C, Pell JK. 2003. Temperature checks the Red Queen? Resistance and virulence in a fluctuating environment. Ecol Lett 6: 2-5.

Boulinier T, Sorci G, Monnat JY, Danchin E. 1997. Parent-offspring regression suggests heritable susceptibility to ectoparasites in a natural population of kittiwake Rissa tridactyla. $J$ Evol Biol 10: 77-85.

Brem RB, Yvert G, Clinton R, Kruglyak L. 2002. Genetic dissection of transcriptional regulation in budding yeast. Science 296: 752-755.

Brown A, Olver W, Donnelly C, May M, Naggert J, Shaffer D, Roopenian D. 2005. Searching QTL by gene expression: Analysis of diabesity. BMC Genet 6: 12.

Carius HJ, Little TJ, Ebert D. 2001. Genetic variation in a hostparasite association: Potential for coevolution and frequency dependent selection. Evolution 55: 1136-1145.

Clarke BC. 1979. The evolution of genetic diversity. Proc R Soc Lond B Biol Sci 205: 453-474.

Colbourne JK, Crease TJ, Weider LJ, Hebert PDN, Dufresne F, Hobaek A. 1998. Phylogenetics and evolution of a circumarctic species complex (Cladocera: Daphnia pulex). Biol J Linn Soc 65: 347-365.

Coltman DW, Pilkington JG, Smith JA, Pemberton JM. 1999. Parasite-mediated selection against inbred Soay sheep in a free-living, island population. Evolution 53: 1259-1267.

Duffy MA, Sivars-Becker L. 2007. Rapid evolution and ecological host-parasite dynamics. Ecol Lett 10: 44-53.

Duncan AB, Little TJ. 2007. Parasite-driven genetic change in a natural population of Daphnia magna. Evolution 61: 796-803.

Duncan A, Mitchell SE, Little TJ. 2006. Parasite-mediated selection in Daphnia: The role of sex and diapause. J Evol Biol 19: 1183-1189.

Ebert D, Zschokke-Rohringer CD, Carius HJ. 1998. Within- and between-population variation for resistance of Daphnia magna to the bacterial endoparasite Pasteuria ramosa. Proc $R$ Soc Lond B Biol Sci 265: 2127-2134.

Ford MJ. 2002. Applications of selective neutrality tests to molecular ecology. Mol Ecol 11: 1245-1262.

Frank SA. 1993. Evolution of host-parasite diversity. Evolution 47: 1721-1732.

Freimoser FM, Hu G, St Leger RJ. 2005. Variation in gene expression patterns as the insect pathogen Metarhizium anisopliae adapts to different host cuticles or nutrient deprivation in vitro. Microbiology 151: 361-371.

Gilbert SC, Plebanski M, Gupta S, Morris J, Cox M, Aidoo M, Kwiatkowski D, Greenwood BM, Whittle HC, Hill AV. 1998. Association of malaria parasite population structure, HLA, and immunological antagonism. Science 279: 1173-1177.

Hamilton WD. 1980. Sex versus non-sex versus parasite. Oikos 35: 282-290.

Hamilton WD, Axelrod R, Tanese R. 1990. Sexual reproduction as an adaptation to resist parasites. Proc Natl Acad Sci 87: 35663573.

Hebert PD. 1974. Enzyme variability in natural populations of Daphnia magna. II. Genotypic frequencies in permanent populations. Genetics 77: 323-334.

Hedrick PW. 1994. Evolutionary genetics of the major histocompatibility complex. Am Nat 143: 945-964.

Hedrick PW. 1998. Balancing selection and MHC. Genetica 104: 207-214.

Hill AVS, Allsopp CEM, Kwiatkowski D, Anstey NM, Twumasi P, Rowe PA, Bennett S, Brewster D, McMichael AJ, Greenwood BM. 1991. Common West African HLA antigens are associated with protection from severe malaria. Nature 352: 595-600.

Hill AVS, Kwiatkowski D, McMichael AJ, Greenwood BM, Bennett S. 1992. Maintenance of Mhc polymorphism: Reply. Nature 355: 403-403.

Hill CA, Kafatos FC, Stansfield SK, Collins FH. 2005. Arthropodborne diseases: Vector control in the genomics era. Nat Rev Microbiol 3: 262-268.

Hurst LD, Smith NGC. 1999. Do essential genes evolve slowly? Curr Biol 9: 747-750.

Jiggins FM, Kim K-W. 2006. Contrasting evolutionary patterns in Drosophila immune receptors. J Mol Evol 63: 769-780.

Keeler CL Jr, Bliss TW, Lavric M, Maughan MN. 2007. A functional genomics approach to the study of avian innate immunity. Cytogenet Genome Res 117: 139-145.

Kover PX, Caicedo AL. 2001. The genetic architecture of disease resistance in plants and the maintenance of recombination by parasites. Mol Ecol 10: 1-16.

Labbé P, Little TJ. 2009. ProPhenolOxidase in Daphnia magna: cDNA sequencing and expression in relation to resistance to pathogens. Dev Comp Immunol 33: 674-680.

Labbé P, McTaggart SJ, Little TJ. 2009. An ancient immunity gene duplication in Daphnia magna: RNA expression and sequence analysis of two nitric oxide synthase genes. Dev Comp Immunol 33: 1000-1010.

Lan Y, Xu X, Yang F, Zhang X. 2006. Transcriptional profile of shrimp white spot syndrome virus (WSSV) genes with DNA microarray. Arch Virol 151: 1723-1733.

Lass S, Ebert D. 2006. Apparent seasonality of parasite dynamics: Analysis of cyclic prevalence patterns. Proc R Soc Lond B Biol Sci 273: 199-206.

Lazzaro BP, Clark AG. 2001. Evidence for recurrent paralogous gene conversion and exceptional allelic divergence in the Attacin genes of Drosophila melanogaster. Genetics 159: 659671.

Lazzaro BP, Clark AG. 2003. Molecular population genetics of inducible antibacterial peptide genes in Drosophila melanogaster. Mol Biol Evol 20: 914-923.

Lazzaro BP, Sceurman BK, Clark AG. 2004. Genetic basis of natural variation in D. melanogaster antibacterial immunity. Science 303: 1873-1876.

Little TJ. 2002. The evolutionary significance of parasitism: Do parasite-driven genetic dynamics occur ex silico? J Evol Biol 15: $1-9$.

Little TJ, Cobbe N. 2005. The evolution of immune-related genes from disease carrying mosquitoes: Diversity in a peptidoglycan- and a thioester-recognising protein. Insect Mol Biol 14: 599-605.

Little TJ, Ebert D. 1999. Associations between parasitism and host genotype in natural populations of Daphnia (Crustacea: Cladocera). J Anim Ecol 68: 134-149.

Little TJ, Ebert D. 2000a. Sex, linkage disequilibrium and pat- 
terns of parasitism in three species of cyclically parthenogenic Daphnia (Crustacea: Cladocera). Heredity 85: 257-265.

Little TJ, Ebert D. 2000b. The cause of parasitic infection in natural populations of Daphnia (Crustacea: Cladocera): The role of host genetics. Proc R Soc Lond B Biol Sci 267: 2037-2042.

Little TJ, Ebert D. 2001. Temporal patterns of genetic variation for resistance and infectivity in a Daphnia-microparasite system. Evolution 55: 1146-1152.

Little TJ, O'Connor B, Colegrave N, Watt K, Read AF. 2003. Maternal transfer of strain-specific immunity in an invertebrate. Curr Biol 13: 489-492.

Little TJ, Colbourne JK, Crease TJ. 2004. Molecular evolution of Daphnia immunity genes: Polymorphism in a gram negative binding protein and an $\alpha-2$-macroglobulin. J Mol Evol 59: 498506.

Lively CM. 1993. Rapid evolution by biological enemies. Trends Ecol Evol 8: 345-346.

Lynch M, Walsh B. 1998. Genetics and analysis of quantitative traits. Sinauer, Sunderland, MA.

Marchese A, Schito GC, Debbia EA. 2000. Evolution of antibiotic resistance in gram-positive pathogens. $J$ Chemother 12: 459 462.

McDonald JH, Kreitman M. 1991. Adaptive protein evolution at the Adh locus in Drosophila. Nature 351: 652-654.

McTaggart S, Conlon C, Colbourne J, Blaxter M, Little T. 2009. The components of the Daphnia pulex immune system as revealed by complete genome sequencing. BMC Genomics 10: 175.

Mitchell SE, Read AF, Little TJ. 2004. The effect of a pathogen epidemic on the susceptibility to infection, reproductive investment and genetic structure of the cyclical parthenogen Daphnia magna. Ecol Lett 7: 848-858.

Mitchell SE, Rogers ES, Little TJ, Read AF. 2005. Host-parasite and genotype-by-environment interactions: Temperature modifies potential for selection by a sterilizing pathogen. Evolution 59: $70-80$

Morgan AD, Gandon S, Buckling A. 2005. The effect of migration on local adaptation in a coevolving host-parasite system. Nature 437: 253-256.

Morse SS. 1994. The evolutionary biology of viruses. Raven, New York.

Niaré O, Markianos K, Volz J, Oduol F, Touré A, Bagayoko M, Sangaré D, Traoré SF, Wang R, Blass C, et al. 2002. Genetic loci affecting resistance to human malaria parasites in a West African mosquito vector population. Science 298: 213-216.

Obbard DJ, Jiggins FM, Little TJ. 2006. Rapid evolution of antiviral RNAi genes. Curr Biol 16: 580-585.

Obbard D, Linton Y, Jiggins F, Yan G, Little T. 2007. Population genetics of Plasmodium resistance genes in Anopheles gambiae: No evidence for strong selection. Mol Ecol 16: 34973510.

Obbard DJ, Callister DM, Jiggins FM, Soares DC, Yan G, Little TJ. 2008. The evolution of TEP1, an exceptionally polymorphic immunity gene in Anopheles gambiae. BMC Evol Biol 8: 274.
Obbard DJ, Welch JJ, Little TJ. 2009. Inferring selection in the Anopheles gambiae species complex: An example from immune-related serine protease inhibitors. Malar J 8: 117.

Osta MA, Christophides GK, Kafatos FC. 2004. Effects of mosquito genes on Plasmodium development. Science 303: 2030 2032.

Rainey P. 2004. Bacterial populations adapt genetically by natural selection even in the lab! Microbiol Today 31: 160-162.

Rivero A. 2006. Nitric oxide: An antiparasitic molecule of invertebrates. Trends Parasitol 22: 219-225.

Sadd BM, Schmid-Hempel R. 2006. Insect immunity shows specificity in protection on secondary pathogen exposure. Curr Biol 16: 1206-1210.

Salathé M, Kouyos RD, Bonhoeffer S. 2008. The state of affairs in the kingdom of the Red Queen. Trends Ecol Evol 23: 439-445.

Schlenke TA, Begun DJ. 2003. Natural selection drives Drosophila immune system evolution. Genetics 164: 1471-1480.

Scott ME. 1991. Heligmosomoides polygrus (Nematoda): Susceptible and resistant strains are indistinguishable following natural infection. Parasitology 103: 429-438.

Seger J. 1988. Dynamics of some simple host-parasite models with more than two genotypes in each species. Philos Trans $R$ Soc Lond B Biol Sci 319: 541-555.

Soderhall K, Cerenius L. 1998. Role of the prophenoloxidase-activating system in invertebrate immunity. Curr Opin Immunol 10: 23-28.

Sorci G, Moller AP, Boulinier T. 1997. Genetics of host-parasite interactions. Trends Ecol Evol 12: 196-200.

Stahl EA, Bishop JG. 2000. Plant-pathogen arms races at the molecular level. Curr Opin Plant Biol 3: 299-304.

Stahl EA, Dwyer G, Mauricio R, Kreitman M, Bergelson J. 1999. Dynamics of disease resistance polymorphism at the Rpml locus of Arabidopsis. Nature 400: 667-671.

Thomas MB, Blanford S. 2003. Thermal biology in insect-parasite interactions. Trends Ecol Evol 18: 344-350.

Thompson JN, Burdon JJ. 1992. Gene-for-gene coevolution between plants and parasites. Nature 360: 121-125.

Vale PF, Stjernman M, Little TJ. 2008. Temperature-dependent costs of parasitism and maintenance of polymorphism under genotype-by-environment interactions. J Evol Biol 21: 14181427.

Vlachou D, Schlegelmilch T, Christophides GK, Kafatos FC. 2005. Functional genomic analysis of midgut epithelial responses in Anopheles during Plasmodium invasion. Curr Biol 15: $1185-1195$.

Wilfert L, Schmid-Hempel P. 2008. The genetic architecture of susceptibility to parasites. BMC Evol Biol 8: 187.

Wolinska J, Keller B, Manca M, Spaak P. 2007. Parasite survey of a Daphnia hybrid complex: Host-specificity and environment determine infection. J Anim Ecol 76: 191-200.

Woolhouse ME, Webster JP, Domingo E, Charlesworth B, Levin BR. 2002. Biological and biomedical implications of the coevolution of pathogens and their hosts. Nat Genet 32: 569-577.

Yang Z, Bielawski JP. 2000. Statistical methods for detecting molecular adaptation. Trends Ecol Evol 15: 496-502. 


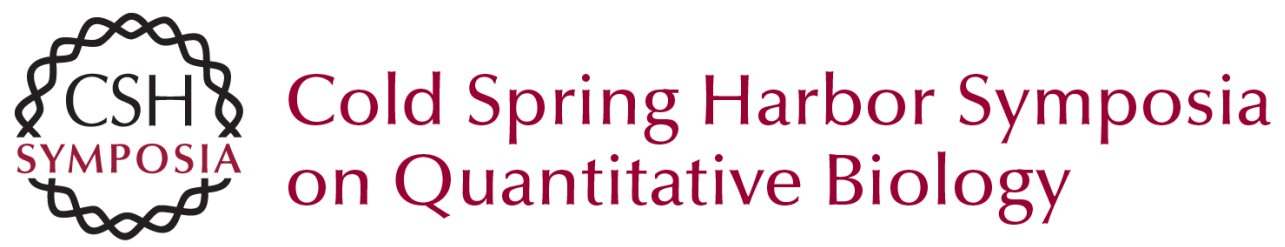

\title{
Exploring the Molecular Landscape of Host-Parasite Coevolution
}

\author{
D.E. Allen and T.J. Little
}

Cold Spring Harb Symp Quant Biol 2009 74: 169-176 originally published online October 20, 2009 Access the most recent version at doi:10.1101/sqb.2009.74.022

References This article cites 80 articles, 7 of which can be accessed free at: http://symposium.cshlp.org/content/74/169.full.html\#ref-list-1

License

Email Alerting Receive free email alerts when new articles cite this article - sign up in the box at the Service top right corner of the article or click here.

To subscribe to Cold Spring Harbor Symposia on Quantitative Biology go to:

http://symposium.cshlp.org/subscriptions 